\title{
A gender study of self-efficacy perceived in Socio-cultural environment in Mexican university students in the health area
}

\author{
Alejandro Chávez Guerrero ${ }^{1}$, Jesús Enrique Peinado Pérez ${ }^{1}$, Juan Francisco Aguirre Chávez ${ }^{1}$, \\ Oswaldo Ceballos Gurrola ${ }^{2}$, Guadalupe Javier Rivero Carrasco ${ }^{1,}$, \\ ${ }^{1}$ Faculty of Physical Culture Sciences, Autonomous University of Chihuahua, México \\ ${ }^{2}$ Faculty of Sport Organization, Autonomous University of Nuevo León, México
}

\section{Email address:}

jrivero@uach.mx (G. J. R. Carrasco)

\section{To cite this article:}

Alejandro Chávez Guerrero, Jesús Enrique Peinado Pérez, Juan Francisco Aguirre Chávez, Oswaldo Ceballos Gurrola, Guadalupe Javier Rivero Carrasco. A Gender Study of Self-Efficacy Perceived in Socio-Cultural Environment in Mexican University Students in the Health Area. Science Journal of Education. Vol. 2, No. 3, 2014, pp. 85-88. doi: 10.11648/j.sjedu.20140203.13

\begin{abstract}
The aim of the present study was to compare the profiles of perceived self-efficacy in the sociocultural sphere between men and women, Mexican university students of health sciences. A total sample of 524 participants (202 women, $322 \mathrm{men})$ aged 17-20 years $(\mathrm{M}=18.20 ; \mathrm{SD}=0.72)$ participated in this study. A quantitative approach with a descriptive and transversal survey design was applied. The results of the one-way multivariate analysis of variance, followed by the one-way univariate analyses of variance, showed that women reported significant higher punctuations than men regarding the perceived self-efficacy in promotion of the culture and cultural identity $(\mathrm{p}<.001)$. Therefore, gender is an important variable when design any kind of intervention for improving the perceived self-efficacy of students in sociocultural sphere. Future research should apply these findings within other cultures.
\end{abstract}

Keywords: Student's Beliefs, Gender Differences, Higher Education, Academic Performance, Students Characteristics

\section{Introduction}

Self-efficacy can be defined as the different judgments individuals make of their own capacities from which they will organize and execute their own acts enabling them to achieve the desired performance [1]; or as the beliefs a person has about his own capacities to organize and execute required ways for action in expected situations or based in levels of performance [2]. Therefore it is not enough to "be able to" but it is precise to conceive a "self- capable of". A self-capable of using personal skills and abilities in different circumstances, even emotional reactions experimented in difficult situations [2-4].

A clear evidence of the importance of self-efficacy in the academic field is that it reveals why people with the same skill and knowledge level present different behaviors and results or why people act dissonant with their abilities $[5,6]$. This explains why an adequate academic performance also depends of perceived self-efficacy to manage academic demands successfully. Therefore, self-efficacy beliefs in the same self-capacity are essential to dominate academic activities because students that trust in their own capacities are more motivates to reach their goals $[7,8]$. Indeed people who doubt of their own capacities can believe that things are even more difficult than they really are; this belief creates stress, depression and narrow vision to solve problems $[7,8]$.

It has been shown that low level of self-efficacy can be responsible not only for the decrease of school performance and interest to study but also of misbehavior in young people [9]. From here, the importance of strengthening with "Education" the development of the academic competence in the students, helping them to build skills that allow them believe in their own capacities $[10,11]$.

This work is a descriptive study, which compares profiles of perceived self-efficacy in a sociocultural environment of university men and women in the health area, trying to provide evidence and data that contributes to educational intervention within an educational perspective of attention to diversity inside the classroom. 


\section{Method}

\subsection{Participants and Design}

A sample of 524 university students, 202 women and 322 men, aged 17-20 years $(\mathrm{M}=18.20 ; \mathrm{SD}=0.72)$ participated in the study. The sample was constituted by all the freshmen university students from each degree in health sciences offered by the Autonomous University of Chihuahua (Mexico). A convenience sampling was used in order to try to cover representation of all the degrees. Regarding the design of the study, a quantitative approach with a descriptive and transversal survey design was used [12]. The independent variable was gender (women and men) and the dependent variables were the mean scores in the four scenarios in both the promotion of the culture and cultural identity.

\subsection{Instrument}

The self-efficacy in promotion of the culture and cultural identity was measured by the Self-efficacy in the Sociocultural Sphere Scale [13]. This questionnaire consists of a nine-item scale with two subscales: promotion of the culture (six items) and cultural identity (three items). According to previous studies $[14,15]$ due to the fact that in the Mexican academic context, a scale from 0 to 10 commonly assesses students, in the present study a
Likert-type scale from 0 to 10 was chosen. For each domain (item) of the promotion of the culture and cultural identity (subscales), the participants were asked about how capable they feel, how much interest they have, and if they would make an effort to change how capable they will be to... Therefore, all the participants responded to each of the nine items (Table 1) of the questionnaire in the three different scenarios: (a) Scenario of perceived ability, responding in the context "how capable I feel to... to manage in each of the domains of the competences above mentioned"; (b) Scenario of interest in being able, responding in the context "how much interest I have in being able to...to manage in each of the domains of the competences above mentioned"; and (c) Scenario of change to be able to, responding into the context "if I would make an effort to change, how much capable I will be able to...to manage in each of the domains of the competences above mentioned".

The internal consistency reliability of the promotion of the culture factor was very high: perceived self-efficacy $\alpha$ $=.902(.888-.914)$, desired self-efficacy $\alpha=.909(.896-.921)$ and reachable self-efficacy $\alpha=.912(.900-.923)$ and the internal consistency reliability of the cultural identity factor was acceptable: perceived self-efficacy $\alpha=.694$ (.646-.737), desired self-efficacy. $\alpha=.702(.655-.744)$ and reachable self-efficacy $\alpha=.701$ (.654-.743).

Table 1. Items of the Self-Efficacy in Sociocultural Scale grouped by factors

\begin{tabular}{ll}
\hline Factor & Item \\
\hline Promotion of the culture & 1. Participate actively in creational processes, conservation and cultural diffusion \\
5. Analyze the phenomena of globalization and sustainable development from different perspectives \\
6. Generate an interaction with the environment, fostering the community level \\
7. Participate in proposals that contribute to the development, and the social and cultural improvement \\
8. Interact with different social groups fostering the quality of life \\
9. Act like promoter of the quality of life \\
2. Act with respect and tolerance \\
3. Demonstrate values before different costumes and differences and toward the multicultural \\
4. Identify myself with the culture of my state and country
\end{tabular}

When calculating the scores for the both dimensions promotion of the culture and cultural identity, four different values were calculated: (1) Perceived self-efficacy, obtained from the average scores in the scenario of perceived ability; (2) Desired self-efficacy, calculated from the average scores in the scenario of interest of being able; (3) Reachable self-efficacy, obtained from the mean scores in the scenario of being able; and (4) Possibility of improvement in the perceived self-efficacy, calculated from the mean difference between reachable self-efficacy and perceived self-efficacy. A higher score indicates greater self-efficacy, whereas a lower score represents lesser self-determination.

\subsection{Procedure}

All freshmen university students from each degree in health sciences offered by the Autonomous University of Chihuahua in the semester January-June of 2012 were invited to participate in this present study. These university students were fully informed about all the features of the project. Then, all the students that had agreed to participate were asked to sign a written informed consent. After the students' approvals were obtained, participants completed the above-mentioned questionnaire by means of the instrument module administrator of the Scales Editor Version 2.0 [16].

Participants completed the questionnaire in the computer rooms of their faculties during a session. At the beginning of the session the researchers gave a general introduction about the importance of the research and how to access the questionnaire thought the software. When the participants were in the editor, the instructions about how to fill out the questionnaire correctly appeared before the instrument. Additionally, the participants were advised to ask for help if confused concerning either the instructions or the clarity of a particular item. Completion of the entire questionnaire 
took approximately 20 minutes. At the end of the session their participation was welcomed. Afterward, when all the participants completed the questionnaire, the data was collected by means of the results generator module of the Scales Editor Version 2.0 [16].

\subsection{Data Analysis}

Descriptive statistics (means and standard deviations) for all the variables were calculated. Subsequently, after verifying that the data met the assumptions of parametric statistical analyses, a one-way multivariate analysis of variance (MANOVA), followed by the one-way univariate analysis of variance (ANOVA), were used to examine the differences between the men and women in both the reported self-efficacy in promotion of the culture and cultural identity scores. Moreover, the effect size was estimated using the eta-squared ( $\eta 2)$. The internal consistency reliability of the each variable was estimated using the Cronbach coefficient alphas and the $95 \%$ confidence intervals (CI). All statistical analyses were performed using the SPSS version 20.0 for Windows (IBM $®$ SPSS $®$ Statistics 20). The statistical significance level was set at $\mathrm{p}<.05$.

\section{Results}

\subsection{Promotion of the Culture Factor}

Table 2 shows the mean values and standard deviations

Table 2. Results of MANOVA for the gender differences in the six variables of self-efficacy for promotion of the culture

\begin{tabular}{llllll}
\hline & Men $(\boldsymbol{n}=\mathbf{3 2 2})$ & Women $(\boldsymbol{n}=\mathbf{2 0 2})$ & $\boldsymbol{F}$ & $\boldsymbol{p}$ & $<.001$ \\
\hline & & & 10.972 & $<.001$ & .060 \\
Perceived self-efficacy & $7.28(1.49)$ & $7.95(1.18)$ & 28.527 & $<.001$ & .052 \\
Desired self-efficacy & $8.08(1.54)$ & $8.72(1.10)$ & 26.524 & $<.001$ & .048 \\
Reachable self-efficacy & $8.59(1.35)$ & $9.15(0.84)$ & 27.904 & .051 \\
Possibility for improving & $1.30(1.00)$ & $1.20(0.94)$ & .1 .371 & .003 \\
perceived self-efficacy & & & .242 & \\
\hline
\end{tabular}

Table 3. Results of MANOVA for the gender differences in the six variables of self-efficacy for cultural identity

\begin{tabular}{|c|c|c|c|c|c|}
\hline & $\operatorname{Men}(n=322)$ & $\operatorname{Women}(n=202)$ & $F$ & $p$ & $\eta 2$ \\
\hline & & & 3.145 & $<.05$ & .018 \\
\hline Perceived self-efficacy & $8.45(1.13)$ & $8.68(1.00)$ & 5.953 & $<.05$ & .011 \\
\hline Desired self-efficacy & $8.99(1.05)$ & $9.26(0.87)$ & $9.267^{*}$ & $<.05$ & .017 \\
\hline Reachable self-efficacy & $9.38(0.77)$ & $9.54(0.61)$ & 6.134 & $<.05$ & .012 \\
\hline $\begin{array}{l}\text { Possibility for improving } \\
\text { perceived self-efficacy }\end{array}$ & $0.94(0.81)$ & $0.86(0.74)$ & 1.253 & .263 & .002 \\
\hline
\end{tabular}

Note. Descriptive values are reported as mean (standard deviation)

\section{Discussion and Conclusions}

The purpose of the present study was to compare the profiles of perceived self-efficacy in promotion of the culture (consisting of participate actively in creational processes, conservation and cultural diffusion; analyze the phenomena of globalization and sustainable development from different perspectives; generate an interaction with the environment, fostering the community level; participate in of the self-efficacy in promotion of the culture, as well as the results of the MANOVA and the follow-up univariate ANOVAs. The MANOVA results indicated overall statistical significant differences between genders in the self-efficacy in promotion of the culture scores (Wilks' $\lambda$ $=.940 ; \mathrm{p}=<.001 ; \eta 2=.060$ ). Subsequently, the follow-up ANOVAs showed that the women reported statistically significant greater perceived, desired, and reachable self-efficacy in promotion of the culture than the men $(\mathrm{F}(1,522)=28.527, \mathrm{p}<.001 ; \mathrm{F}(, 522)=26.524, \mathrm{p}$ $<.001$; and $\mathrm{F}(1,522)=27.904, \mathrm{p}<.001$, respectively). However, in the possibility for improving self-efficacy statistically significant differences were not found $(\mathrm{p}>.05)$.

\subsection{Cultural Identity Factor}

Table 3 shows the mean values and standard deviations of the self-efficacy in cultural identity, as well as the results of the MANOVA and the follow-up univariate ANOVAs. The MANOVA results indicated overall statistical significant differences between genders in the self-efficacy in cultural identity scores (Wilks' $\lambda=.982 ; \mathrm{p}<.05 ; \eta 2$ $=.018)$. Subsequently, the follow-up ANOVAs showed that the women reported statistically significant better punctuations in perceived, desired and reachable self-efficacy in cultural identity than the men $(\mathrm{F}(1,522)=$ $5.953, \mathrm{p}<.05 ; \mathrm{F}(1,522)=9.267, \mathrm{p}<.05 ;$ and $\mathrm{F}(1,522)=$ $6.134, \mathrm{p}<.05$, respectively).

7 
levels of self-efficacy than men in the two factor analyzed (promotion of the culture and cultural identity what can be concluded that women show greater security and desire to succeed in the sociocultural field showing the men; conclusion that in general agreement with the results of studies on gender differences in college students [17] and high school students [18], where it was also found that women reported higher levels of self-efficacy than men. Differences according to the theory of self-efficacy Bandura [1] can be explained because the process of socialization results in men and women have a different perception about the tasks that are most appropriate for each gender activities giving rise to different expectations of self-efficacy.

\section{Acknowledgements}

This study is part of a project funded by the "Secretaría de Educación Pública Sub-secretaría de Educación Superior-Dirección General de Educación Superior Universitaria de México" [Mexican Ministry of Education-Department of Higher Education-General Directorate of the University Education] (OF-13-6894).

\section{References}

[1] Bandura. Self-efficacy: The exercise of Control. New York: Freeman, 1997.

[2] H. Blanco, M. Martínez, M. Ornelas, F. J. Flores, F. J., \&J. E. Peinado. Validation of self-efficacy scales in academic behaviors and health care. México: Doble Hélice Ediciones, 2011.

[3] M. Ornelas, H. Blanco, G. Gastélum \& A. Chávez. Perceived self-efficacy in the University Student Academic Conduct. University Formation, vol. 5(2), pp 17-26, 2012.

[4] V. Schmidt, N. Messoulam \& F. Molina. Academic self-concept in middle school adolescents: presentation of an instrument for evaluation. Iberoamerican Journal of Psychological Diagnostic and Assessment, Vol. 1(25), pp. 81-106, 2008.

[5] A. Bandura. Self-efficacy mechanism inhuman agency. American Psychologist, Vol. 37(2), pp. 122-147, 1982.

[6] E. Pérez, C. Lescano, D. Heredia, P. Zalazar, L. Furlám \& M. Martínez. Development and psychometric analysis of self-efficacy inventory for multiple intelligences in Argentine children. Psicoperspectivas, Vol. 10(1), pp. 169-189, 2011.

[7] A. Blanco. Self-efficacy beliefs of college students: an empirical study on the specificity of the construct. RELIEVE, Vol. 16(1), pp. 1-28, 2010.

[8] M. N. Rodríguez. Confirmatory factor analysis of the Uruguayan version of the Smart Trapnell scale to measure perceived intellectual ability. Iberoamerican Journal of
Psychological Diagnostic and Assessment, Vol. 1(27), pp. 85-105, 2009.

[9] Zimmerman \& A. Kitsantas, A. Homework practice and academic achievement. The mediating role of self-efficacy and perceived responsibility beliefs. Contemporary Educational Psychology, Vol. 30(4), pp. 397-417, 2005.

[10] M. A. Carbonero \&E. Merino. Self-efficacy and vocational maturity. Psicothema, Vol. 16(2), pp. 229-234, 2008.

[11] M. A. Carbonero \& E. Merino. Autoeficacia y madurez vocacional. Psicothema, Vol. 16(2), pp. 229-234, 2008.

[12] M. Ornelas, H. Blanco, J. M. Rodríguez \&F. J. Flores. Psychometric analysis of the self-efficacy scale with care behaviors of physical health in college freshmen. University Education, Vol. 4(6), pp. 21-34, 2011.

[13] M. Ornelas, H. Blanco, J. M. Rodríguez \& F. J. Flores. Análisis psicométrico de la escala autoeficacia en conductas de cuidado de la salud física en universitarios de primer ingreso. Formación Universitaria, Vol. 4(6), pp. 21-34, 2011.

[14] R. Hernández, C. Fernández \&P. Baptista. Research Methodology. México: McGraw- Hill, 2010.

[15] R. Hernández, C. Fernández \& P. Baptista. Metodología de la investigación. México: McGraw- Hill, 2010.

[16] F. Muñoz, M. C. Zueck, G Gastélum, \&J. C. Guedea. Factorial composition of a self-efficacy scale in the sociocultural environment in engineering college. University Education, Vol. 5(5), pp. 39-50, 2012.

[17] H. Blanco, M. Martínez, M. d. C. Zueck \& G. Gastélum. Psychometric analysis of the self-efficacy scale in academic behaviors in college freshmen. Investigative News in Education, Vol. 11(3), pp. 1-27 (2011).

[18] J. Viciana, E. M. Cervelló \&J. Ramírez. Effects of manipulating positive and negative feedback on goal orientation, perceived motivational climate, satisfaction, task choice, perception of ability, and attitude to physical education lessons. Perceptual and motor skills, Vol. 105(1), pp. 67-82, 2007.

[19] H. Blanco, M. Ornelas, J. L. Tristán, A. Cocca, D. Mayorga-Vega, J. López-Walle \&J. Viciana. Editor for creating and applying computerise surveys. Procedia Social and Behavioral Sciences, Vol. 106, pp. 935-940, 2013. doi: http://dx.doi.org/10.1016/j.sbspro.2013.12.105

[20] J. E. Peinado. Effect of academic discipline on the perception of basic skills in college quiting. España: Universidad de Granada, 2011.

[21] J. E. Peinado. Efecto de la disciplina académica sobre la percepción de las competencias básicas en universitarios chihuahuenses. España: Universidad de Granada, 2011.

[22] J. Saunders, L. Davis, T. Williams \& J H. Williams. Gender differences in self perceptions and academic outcomes: A study of African-American high school students. Journal of Youth and Adolescence, Vol. 33(1), pp. 81-90, 2004. 